CLINICAL STUDY

\title{
Changes in coagulation indexes and occurrence of venous thromboembolism in patients with Cushing's syndrome: results from a prospective study before and after surgery
}

\author{
Luca Manetti, Fausto Bogazzi, Clara Giovannetti, Valentina Raffaelli, Maura Genovesi, Giovanni Pellegrini ${ }^{1}$, \\ Lucia Ruocco $^{1}$, Aldo Iannelli ${ }^{2}$ and Enio Martino \\ Department of Endocrinology, University of Pisa, Ospedale Cisanello, Via Paradisa 2, 56124 Pisa, Italy, ${ }^{1}$ Clinical Chemistry Laboratory, Azienda \\ Ospedaliero-Universitaria Pisana, 56124 Pisa, Italy and ${ }^{2}$ Department of Neuroscience, University of Pisa, 56124 Pisa, Italy
}

(Correspondence should be addressed to L Manetti; Email: lmanetti@endoc.med.unipi.it)

\begin{abstract}
Objectives: To evaluate whether patients with Cushing's syndrome (CS) had i) changes in coagulative and fibrinolytic parameters associated with CS activity and ii) higher prevalence of venous thromboembolic events (VTE).

Design: Prospective study conducted on patients with CS evaluated at diagnosis and 12 months after surgery.

Patients and methods: Forty patients with active CS (36 with Cushing's disease (CD) and 4 with an adrenal adenoma) were evaluated. Forty normal subjects and 70 patients with non-ACTH-secreting pituitary adenomas served as controls. All patients and controls underwent an assessment of coagulation and fibrinolysis indexes before and after surgery.

Results: CS patients at baseline had a hypercoagulative phenotype when compared with normal subjects (activated partial thromboplastin time (aPTT), fibrinogen, D-Dimer, von Willebrand factor (VWF), plasminogen activator inhibitor 1 (PAI-1 or SERPINE1), antithrombin III (ATIII or SERPINC1), $P<0.0001, \alpha_{2}$ antiplasmin, $P=0.0004$, thrombin-antithrombin complex (TAT), $P=0.01$, factor IX (F9), $P=0.03)$. Patients with still active disease after surgery had higher coagulative parameters than those in remission (VWF $(P<0.0001)$, PAI-1 $(P=0.004)$, TAT $(P=0.0001)$, ATIII $(P=0.0002)$ and $\alpha_{2}$ antiplasmin (or SERPINF2; $P=0.006)$ ), whereas aPTT levels $(P=0.007)$ were significantly reduced. VTE occurred in three patients with CD (7.5\%): one had a pulmonary embolism and two patients had a deep venous thrombosis; no patients submitted to transsphenoidal surgery for non-Cushing's pituitary adenoma had VTE $(P=0.04)$.

Conclusions: Patients with CS have a procoagulative phenotype due to cortisol-associated changes in haemostatic and fibrinolytic markers, leading to increased incidence of VTE. Thromboprophylaxis seems to be appropriated in patients with active disease, particularly in the postoperative period.
\end{abstract}

European Journal of Endocrinology 163 783-791

\section{Introduction}

Endogenous Cushing's syndrome (CS) is a clinical state sustained by prolonged, inappropriate exposure to excessive endogenous secretion of cortisol. This condition may result from excessive ACTH production from the pituitary gland, ectopic ACTH secretion or excessive autonomous secretion of cortisol from a hyperfunctioning adrenocortical tumour. CS is associated with central obesity, hypertension, diabetes or insulin resistance, conditions that lead to an increased cardiovascular and thromboembolic risk (1-4). Moreover, it has been demonstrated that CS is associated with a hypercoagulable state and increased incidence of venous thromboembolic events (VTE) (5-9). Some studies showed a shortening of the activated partial thromboplastin time (aPTT) (10-12) and elevated levels of factor VIII (F8), factor IX (F9) and von Willebrand factor (VWF) in CS with a consequent increased prevalence of cardiovascular disease such as ischaemic disease, cerebrovascular disease, vascular peripheral and lung disorders (10-18). Patients with CS also showed an impairment of the fibrinolytic system due to an excess of the fast-activating plasminogen activator inhibitor 1 (PAI-1 or SERPINE1) (19). A recent retrospective observational study showed that prophylactic anticoagulant therapy may reduce the incidence of VTE in a large cohort of patients with hypercortisolism (9). These data support the evidence of a severe prothrombotic state in CS and mark the importance of a correct assessment of thromboembolic risk in these patients to prevent VTE. 
The aims of this prospective study were to evaluate whether patients with CS had i) changes in coagulative and fibrinolytic parameters associated with CS activity and ii) higher prevalence of VTE.

\section{Patients and methods}

\section{Study population}

Forty patients (32 women, 8 men, 20-65 years) with untreated CS were enrolled in the study after their informed consent had been obtained. Thirty-six patients were affected by Cushing's disease (CD) caused by a corticotroph pituitary adenoma (32 micro- and 4 macroadenoma), and four had an adrenal adenoma (AA). Diagnosis of CD was mainly based on i) clinical features of hypercortisolism; ii) absence of a circadian rhythm of serum cortisol in terms of an elevated midnight sleeping cortisol level; iii) elevated 24-h urinary free cortisol (UFC) level (at least 1.5-2 times the upper limit of normal range) with inappropriately high morning plasma ACTH concentrations $(>20 \mathrm{pg} / \mathrm{ml})$; iv) failure of serum cortisol suppression $(<18 \mathrm{ng} / \mathrm{ml})$ after low-dose dexamethasone suppression test (LDDST) but $>50 \%$ decrease after high-dose oral dexamethasone suppression test overnight (HDDST); v) magnetic resonance imaging (MRI) confirmation of a pituitary micro- or macroadenoma and vi) inferior petrosal sinus gradient $>3$ after CRH stimulation when appropriate. Diagnosis of ACTH-independent CS was based on points i) and ii) associated with elevated UFC levels and suppressed morning plasma ACTH concentrations $(<10 \mathrm{pg} / \mathrm{ml})$ and the evidence of an adrenal lesion by computed tomography (CT) scan $(20,21)$.

Hypertension was present in 24 of $40(60 \%)$ patients and was treated by a different combination of antihypertensive drugs, whereas diabetes mellitus was present in $10(25 \%)$ patients under dietary and medical therapies. At the time of haemostatic and fibrinolytic marker evaluations, no patient was taking drugs to affect coagulation tests or assumed oestrogen therapy, which could affect cortisol concentrations. All CS patients submitted to adrenal and pituitary surgery started replacement therapy with cortone acetate at a total dose of 25-37.5 mg daily in two administrations, immediately after the operation. Subsequently, when adrenal function was recovered, the replacement therapy was tapered and then interrupted. Among patients with AA, all recovered a normal adrenal function between 3 and 6 months after surgery. Among 13 patients with persistent CD, 11 stopped cortone acetate few weeks after surgery, while 2 patients interrupted glucocorticoid replacement therapy between 4 and 5 months after surgery. Among 27 patients with remission of disease, 20 did not receive any glucocorticoid replacement therapy, while 7 patients received $25-37.5 \mathrm{mg}$ of cortone acetate daily in two administrations. At 12 months, all patients with glucocorticoid replacement therapy showed normal serum cortisol and plasma ACTH values after $2-3 \mathrm{~h}$ from the administration of cortone acetate. In these patients, serum electrolytes and blood pressure were normal. No patients with CS had a positive family history of clotting disorders or VTE.

Forty normal subjects ( 29 women and 11 men, 24-65 years) included in the study at a 1:1 ratio and matched for sex and age served as controls for comparing coagulation indexes (coagulation controls). In the period 2005-2008, 55 patients (22 women and 33 men, 28-68 years) with non-functioning pituitary macroadenoma and 15 patients (9 women and 6 men, 24-62 years) with GH-secreting micro- and macroadenoma were submitted to pituitary adenomectomy. There was statistically significant difference in body mass index (BMI) between untreated $C D$ versus coagulation control $(P=0.0013)$ and VTE control $(P<0.0001)$. Among the 55 patients with non-functioning pituitary macroadenoma submitted to pituitary adenomectomy, 2 patients (3.6\%) had complete hypopituitarism, 19 (34.5\%) had partial hypopituitarism, 7 (12.7\%) had isolated GH deficiency (GHD) and $2(3.6 \%)$ presented isolated hypogonadism secondary to hyperprolactinaemia due to pituitary stalk compression. In all patients, pituitary dysfunction was corrected with appropriate replacement therapy with the exception of GH that was not administered to the GHD patients until the disappearance or the stability of the pituitary lesion was proven by MRI. Among the 15 patients with acromegaly, 9 patients were well controlled by somatostatin analogues therapy, while 6 patients had insulin-like growth factor 1 values above the normal range, despite somatostatin therapy. This control group was used for comparing the effects of surgery on VTE (VTE controls). No control subject or non-CS patient submitted to surgery had a predisposing condition and familiarity for VTE. The main clinical features of patients and controls at the study entry are shown in Table 1.

\section{Study design}

This is a prospective study conducted at the Department of Endocrinology, University of Pisa, from January 2005 to January 2008. The study was approved by the Ethical Board of the Department of Endocrinology. At baseline, the study protocol included an accurate clinical history and a physical examination with the evaluation of BMI, systolic and diastolic blood pressure and heart rate. The hormonal evaluation included a blood sample for measuring serum cortisol obtained at 0800, 1600 and $2400 \mathrm{~h}$, for plasma ACTH at $0800 \mathrm{~h}$ and for UFC, for which the mean of two urinary collections was considered. $\mathrm{CRH}$ test was performed after the i.v. administration of $100 \mu \mathrm{g}$ ovine $\mathrm{CRH}$ Dexamethasone at a dose of $0.5 \mathrm{mg}$ for the LDDST was administered 
Table 1 Clinical and biochemical features of patients with Cushing's syndrome and control subjects.

\begin{tabular}{llll}
\hline & Untreated & Coagulation control & VTE control \\
\hline $\begin{array}{l}\text { Number of patients } \\
\text { NF pituitary adenoma }\end{array}$ & 40 & 40 & 70 \\
GH-secreting adenoma & & & 55 \\
Female/male & $32 / 8$ & $29 / 11$ & 15 \\
Age \pm s.D. (years) & $46 \pm 15$ & $44 \pm 11$ & $31 / 39$ \\
BMl \pm s.D. & $31.3 \pm 6.3$ & $28.1 \pm 3.0$ & $49 \pm 12$ \\
CD/CS & $36 / 4$ & - & - \\
Cortisol \pm s.D. $(\mathrm{ng} / \mathrm{ml})$ & $296 \pm 102$ & $185 \pm 36$ & $135 \pm 47$ \\
ACTH \pm s.D. $(\mathrm{pg} / \mathrm{ml})$ & - & $37.1 \pm 10.0$ & $23.3 \pm 14.7$ \\
CD & $51.2 \pm 21.3$ & - & - \\
CS & $5.0 \pm 2.5$ & - & - \\
UFC \pm s.D. $(\mu \mathrm{g} / 24 \mathrm{~h})$ & $267 \pm 120$ & $71.0 \pm 17.6$ & - \\
LDDST: cortisol \pm s.D. $(\mathrm{ng} / \mathrm{ml})$ & $165 \pm 111$ & - & - \\
\hline
\end{tabular}

Untreated, patients with untreated Cushing's syndrome; coagulation control, normal subjects for comparing coagulation indexes; VTE controls, patients with non-functioning (NF) pituitary adenoma or GH-secreting adenoma submitted to surgery; CD, Cushing's disease; CS, Cushing's syndrome; UFC, urinary free cortisol; LDDST, low-dose dexamethasone suppression test.

orally strictly every $6 \mathrm{~h}$ for $48 \mathrm{~h}$, and at a dose of $8 \mathrm{mg}$ for the HDDST administered at $2400 \mathrm{~h}$. Blood samples were collected for serum cortisol measurement at 0800 after $48 \mathrm{~h}$ following the first dose of dexamethasone for LDDST and at 0800 the next morning following a high dose of dexamethasone. MRI confirmation of a pituitary micro- and macroadenoma or an inferior petrosal sinus sample (IPSS) was performed when required. Patients with $\mathrm{CD}$ underwent transsphenoidal surgery, while those with AA were treated by laparoscopic adrenalectomy. A confirmed diagnosis of CD or AA was made on the basis of demonstration of pituitary corticotroph adenoma or AA at pathological examination. The decision to treat $\mathrm{CD}$ and AA with surgery was taken independently from the coagulation conditions. Patients were strictly monitored for 15 days after surgery; subsequent evaluations were made 1, 3, 6 and 12 months after surgery, including serum cortisol at $0800 \mathrm{~h}$, plasma ACTH at $0800 \mathrm{~h}$ and UFC measurements. Coagulation and fibrinolysis indexes were evaluated at enrolment in the study and after 12 months after the definition of persistence/recurrence or remission of hypercortisolism.

Diagnosis of remission was based on i) regression or disappearance of clinical features of hypercortisolism; ii) restored circadian rhythm of serum cortisol; iii) normal UFC levels; iv) normal cortisol suppression after low-dose dexamethasone test; v) normal plasma ACTH concentrations $(>15 \mathrm{pg} / \mathrm{ml})$ for $\mathrm{AA}$ and vi) the absence of pituitary or adrenal lesion by MRI or CT scan $(20,21)$.

Although CS is believed to be associated with an increased occurrence of VTE, no prospective study showing the efficacy of anticoagulant therapy have been reported so far; therefore, prophylaxis is not performed routinely in our Department. IPSS was performed in 19 patients with ACTH-secreting pituitary microadenoma. All patients, after IPSS, underwent antithrombotic prophylaxis with subcutaneous nadroparin calcium, a low molecular-weight heparin, at doses of 5700-7600 IU for 2 weeks.

All patients with CS and those with non-functioning pituitary adenoma and acromegaly were submitted to an accurate clinical history and a physical examination. The diagnosis of deep vein thrombosis (DVT) was performed by an ultrasound compression technique and confirmed by phlebography. The diagnosis of pulmonary embolism was performed by perfusion pulmonary scan.

\section{Hormone assays}

Serum cortisol (Immunotech, Marseille, France), plasma ACTH (Nichols Institute Diagnostics, San Juan Capistrano, CA, USA) and UFC (DSL-2100 active, cortisol RIA, Webster, TX, USA) were assayed by commercial kits. Normal values used in our laboratory were as follows: early morning cortisol, $85-260 \mathrm{ng} / \mathrm{ml}$; ACTH, 9-52 pg/ml and UFC, 36-120 $\mu \mathrm{g} / 24 \mathrm{~h}$.

\section{Coagulation and fibrinolysis evaluation}

All patients and coagulation controls underwent an assessment of coagulative and fibrinolytic markers before (time 0 ) and after surgery (time 12 months). The $\mathrm{ABO}$ blood group was evaluated in patients and controls. All coagulation and fibrinolysis indexes were performed immediately. aPTT (coagulative assay, I.L./T.O.P., range values: 25-39 s), fibrinogen (coagulative assay, I.L./T.O.P., range values: $200-450 \mathrm{mg} / \mathrm{dl}$ ), D-Dimer (turbidimetric immunoassay, I.L./T.O.P., normal value: $<0.5 \mathrm{mg} / \mathrm{l})$, prothrombin fragment $1+2(\mathrm{~F} 1+2$, coagulative assay, I.L./T.O.P., range values: $0.4-1.1 \mathrm{nmol} / \mathrm{l}$ ), factor $\mathrm{V}$ coagulant activity (F5, coagulative assay, I.L./T.O.P., range values: $70-120 \%$ ), factor VII coagulant activity (F7, coagulative assay, I.L./T.O.P., range values: $70-130 \%$ ), F8 coagulant activity (coagulative assay, I.L./T.O.P., range values: $60-150 \%$ ), 
VWF antigen (turbidimetric immunoassay, I.L./T.O.P., range values: 40-126\%), F9 coagulant activity (coagulative assay, I.L./T.O.P., range values 60-150\%), factor XII coagulant activity (F12, coagulative assay, I.L./T.O.P., range values: 60-140\%), plasminogen (PLG) (chromogenic assay, I.L./T.O.P., range values: 70-130\%), S-protein (turbidimetric immunoassay, I.L./T.O.P., range values: 53-109.1\%), C-protein (chromogenic assay, I.L./T.O.P., range values: 70-140\%), PAI-1 (or SERPINE1) antigen (immunoenzymatic assay, Hyphen, range values: 2-47 ng/ml), thrombin-antithrombin complex (TAT, coagulative assay, I.L./T.O.P., range values: $1-4.1 \mu \mathrm{g} / \mathrm{l})$, antithrombin III (ATIII or SERPINC1, chromogenic assay, anti X, I.L. T.O.P., range values: $80-120 \%$ ), $\alpha_{2}$ antiplasmin (chromogenic assay, I.L./T.O.P., range values: $70-130 \%$ ) were assayed by commercial kits in all patients and controls. Considering that VWF concentrations are regulated by $\mathrm{ABO}$ blood group, normal values after correction were 40-126\% for group 0 and 49-163\% for group non-0.

\section{Statistical analysis}

Data were expressed as mean \pm s.D. for quantitative variables and as absolute frequency and percentage for qualitative variables. The comparison between patients and controls for quantitative variables was performed by the non-parametric Mann-Whitney test. The relationships among serum cortisol, UFC and coagulation and fibrinolysis indexes were evaluated by linear regression analysis. The comparison between patients before and after surgery for quantitative variables was performed by the non-parametric Mann-Whitney test. The comparison between untreated patients and patients in remission or persistency after surgery for quantitative variables was performed by the non-parametric Wilcoxon signed rank test for comparing two paired groups. Fisher's exact test for qualitative variables was used to compare the number of patients with coagulation indexes out of normal ranges before and after surgery and to compare VTE occurrence in CS patients and control group. The statistical significance was determined using the exact $P$ value. A $P<0.05$ was considered as significant.

\section{Results}

\section{Coagulation and fibrinolysis indexes at baseline}

Patients with untreated CS had procoagulative phenotype owing to higher values of fibrinogen, D-Dimer, PAI-1, ATIII $(P<0.0001)$, VWF (blood group $0, P=0.007$; blood group non-0, $P<0.0001), \quad \alpha_{2}$ antiplasmin $(P=0.0004)$, TAT $(P=0.01)$, F9 $(P=0.03)$, and a reduction of aPTT levels $(P<0.0001)$ than controls (Table 2). No correlations at baseline were found among coagulation, fibrinolysis indexes and serum cortisol or UFC. We did not find any association between BMI and haemostatic variables (data not shown).

Table 2 Comparison of coagulation and fibrinolysis indexes between patients with untreated Cushing's syndrome and normal subjects.

\begin{tabular}{lccc}
\hline & $\begin{array}{c}\text { Untreated } \\
(n=40)\end{array}$ & $\begin{array}{c}\text { Coagulation } \\
\text { control }(n=40)\end{array}$ & $\boldsymbol{P}$ \\
\hline aPTT \pm s.D. $(\mathrm{s})$ & $27.8 \pm 2.4$ & $34.0 \pm 2.2$ & $<0.0001$ \\
Fibrinogen \pm s.D. $(\mathrm{mg} / \mathrm{dl})$ & $394.7 \pm 88.8$ & $286.2 \pm 46.9$ & $<0.0001$ \\
D-Dimer \pm s.D. $(\mathrm{mg} / \mathrm{l})$ & $0.48 \pm 0.39$ & $0.22 \pm 0.06$ & $<0.0001$ \\
F1 $+2 \pm$ s.D. $(\mathrm{nmol} / \mathrm{l})$ & $0.50 \pm 0.32$ & $0.54 \pm 0.16$ & 0.29 \\
F5 \pm s.D. $(\%)$ & $111.5 \pm 42.6$ & $102.2 \pm 12.7$ & 0.39 \\
F7 \pm s.D. $(\%)$ & $103.0 \pm 22.3$ & $97.6 \pm 24.1$ & 0.41 \\
F8 \pm s.D. $(\%)$ & $121.7 \pm 52.4$ & $109.0 \pm 11.8$ & 0.85 \\
aVWF \pm s.D. $(\%)$ All & $148.8 \pm 71.0$ & $84.4 \pm 20.9$ & $<0.0001$ \\
Blood group 0 $(n=21 / 21)$ & $120.6 \pm 60.5$ & $83.8 \pm 21.1$ & 0.007 \\
Blood group non-0 $(n=19 / 19)$ & $183.6 \pm 69.1$ & $86.7 \pm 24.2$ & $<0.0001$ \\
F9 \pm s.D. $(\%)$ & $127.2 \pm 27.9$ & $119.3 \pm 13.7$ & 0.03 \\
F12 \pm s.D. $(\%)$ & $100.3 \pm 26.1$ & $96.1 \pm 22.3$ & 0.46 \\
Plasminogen \pm s.D. $(\%)$ & $93.7 \pm 16.9$ & $97.7 \pm 9.9$ & 0.15 \\
S-Protein \pm s.D. $(\%)$ & $85.6 \pm 21.9$ & $91.1 \pm 15.3$ & 0.21 \\
C-Protein \pm s.D. $(\%)$ & $129.1 \pm 27.7$ & $120.0 \pm 19.3$ & 0.17 \\
PAl-1 \pm s.D. $(\mathrm{ng} / \mathrm{ml})$ & $45.6 \pm 21.3$ & $15.6 \pm 11.2$ & $<0.0001$ \\
TAT \pm s.D. $(\mu \mathrm{g} / \mathrm{l})$ & $7.2 \pm 6.0$ & $3.0 \pm 1.4$ & 0.01 \\
ATIII \pm s.D. $(\%)$ & $116.9 \pm 11.4$ & $101.6 \pm 9.4$ & $<0.0001$ \\
$\alpha_{2}$ antiplasmin \pm s.D. $(\%)$ & $107.7 \pm 17.3$ & $99.9 \pm 8.9$ & 0.0004 \\
\hline
\end{tabular}

Untreated, patients with untreated Cushing's syndrome; coagulation control, normal subjects for comparing coagulation indexes. aPTT, activated partial thromboplastin time; $\mathrm{F} 1+2$, prothrombin fragment $1+2 ; \mathrm{F} 5$, factor V; F7, factor VII; F8, factor VIII; VWF, von Willebrand factor; F9, factor IX; F12, factor XII; PAI-1, plasminogen activator inhibitor 1; TAT, thrombin-antithrombin complex; ATIII, antithrombin III.

aVWF in all patients and after blood group correction. 


\section{Coagulation and fibrinolysis indexes after surgery}

All patients with CS were submitted to pituitary adenomectomy or adrenalectomy, as appropriate. Mean VWF (all, $P=0.006$; blood group $0, P=0.1$; blood group non-0, $P=0.05)$, PAI-1 $(P=0.05)$, TAT $(P=0.01)$, ATIII $(P=0.002)$, plasminogen $(P=0.04)$ and $\alpha_{2}$ antiplasmin $(P=0.02)$ were significantly reduced after surgery. On the contrary, the other coagulation indexes did not change after surgery.

Twenty-seven out of forty patients $(67.5 \%)$ had remission of disease: all patients with adrenal disease and 23 of those with pituitary disease. The remaining 13 patients had persistent hypercortisolism. Patients with still active disease after surgery had higher coagulative parameters than those with cured disease (VWF (all, $P<0.0001$; blood group $0, P=0.007$; blood group non-0, $P=0.003)$, PAI-1 $(P=0.004)$, TAT $(P=0.0001)$, ATIII $(P=0.0002)$ and $\alpha_{2}$ antiplasmin $(P=0.006))$, whereas aPTT levels $(P=0.007)$ were significantly reduced (Table 3 and Fig. 1).

Changes in coagulation indexes in each patient before and after surgery are shown in Table 4 . The number of patients with VWF (all, $P=0.0003$, blood group non-0, $P=0.004)$ and ATIII $(P=0.001)$ above normal ranges was higher in the untreated group than in patients with remission of disease after surgery (Fig. 1 and Table 4).

\section{Incidence of VTE in the study groups}

VTE occurred in three patients with $\mathrm{CD}(7.5 \%)$, whereas no thromboembolic events occurred in patients with remission of the disease $(P=0.02)$ : one had a pulmonary embolism (2 days after transsphenoidal surgery), whereas 2 patients had deep vein thrombosis (one before surgery and one 2 months after surgery, while hypercortisolism was persistent). The two patients with DVT and the patient with pulmonary embolism (PE) had clearly abnormal coagulation parameters (Table 5). On the contrary, 55 patients with nonfunctioning pituitary macroadenoma and 15 patients with acromegaly due to GH-secreting pituitary microor macroadenoma did not have thromboembolic events neither before nor after surgery $(P=0.04)$.

\section{Discussion}

The presence of procoagulative phenotype, which may be responsible for the increased risk of VTE, has already been described in patients with CS (22). However, a recent systematic review focussed attention on the absence of a high-quality study (23). The causes were several i) absence of prospective studies due to the rarity of the disease; ii) limited number of the coagulation test performed; iii) negligence in defining patients and control groups; iv) unclear timing of coagulation tests; v) inadequacy of follow-up period and vi) poor attention focussing on the occurrence of VTE.

The current data provide the largest perspective study conducted in patients with CS before and after surgery and in normal subjects. These data suggest that patients with CS showed increased levels of fibrinogen, D-Dimer, VWF, PAI-1, ATIII $(P<0.0001), \alpha_{2}$ antiplasmin $(P=0.0004)$, TAT $(P=0.01)$ and F9 $(P=0.03)$ and reduced levels of aPTT $(P<0.0001)$ compared with

Table 3 Comparison of coagulation and fibrinolysis indexes in patients with Cushing's syndrome before and after surgical therapy.

\begin{tabular}{|c|c|c|c|c|c|c|}
\hline & $\begin{array}{l}\text { Untreated } \\
\qquad(n=27)\end{array}$ & $\begin{array}{l}\text { Remission } \\
\quad(n=27)\end{array}$ & $\boldsymbol{P}$ & $\begin{array}{l}\text { Untreated } \\
\qquad(n=13)\end{array}$ & $\begin{array}{l}\text { Persistent } \\
\quad(n=13)\end{array}$ & $\boldsymbol{P}$ \\
\hline aPTT \pm s.D. (s) & $27.9 \pm 2.0$ & $30.7 \pm 3.5$ & 0.007 & $27.7 \pm 3.2$ & $28.4 \pm 2.5$ & 0.34 \\
\hline Fibrinogen \pm s.D. $(\mathrm{mg} / \mathrm{dl})$ & $391.4 \pm 92.3$ & $361.0 \pm 79.3$ & 0.40 & $401.7 \pm 84.5$ & $395.0 \pm 76.4$ & 0.69 \\
\hline D-Dimer \pm s.D. $(\mathrm{mg} / \mathrm{l})$ & $0.49 \pm 0.45$ & $0.33 \pm 0.19$ & 0.28 & $0.47 \pm 0.25$ & $0.45 \pm 0.27$ & 0.67 \\
\hline $\mathrm{F} 1+2 \pm$ s.D. $(\mathrm{nmol} / \mathrm{l})$ & $0.48 \pm 0.30$ & $0.41 \pm 0.37$ & 0.98 & $0.53 \pm 0.37$ & $0.31 \pm 0.20$ & 0.16 \\
\hline F5土S.D. (\%) & $108.2 \pm 49.9$ & $113.8 \pm 1.0$ & 0.17 & $114.7 \pm 37.5$ & $107.1 \pm 8.1$ & 0.67 \\
\hline F7士s.D. (\%) & $102.3 \pm 21.8$ & $95.7 \pm 25.9$ & 0.17 & $104.3 \pm 24.1$ & $104.5 \pm 24.6$ & 0.92 \\
\hline F8土s.D. (\%) & $122.2 \pm 53.3$ & $112.2 \pm 41.4$ & 0.98 & $120.8 \pm 52.9$ & $108.0 \pm 69.4$ & 0.62 \\
\hline${ }^{a} V \bar{W} F \pm$ s.D. (\%) All & $153.5 \pm 73.6$ & $82.4 \pm 29.7$ & $<0.0001$ & $138.5 \pm 67.1$ & $167.5 \pm 97.0$ & 0.42 \\
\hline Blood group $0(n=13 / 8)$ & $120.3 \pm 71.0$ & $71.3 \pm 25.8$ & 0.007 & $121.0 \pm 42.6$ & $146.8 \pm 66.1$ & 0.49 \\
\hline Blood group non-0 $(n=14 / 5)$ & $186.6 \pm 62.2$ & $95.5 \pm 29.8$ & 0.003 & $173.7 \pm 99.1$ & $196.4 \pm 132.5$ & 0.46 \\
\hline F9土s.D. (\%) & $124.2 \pm 31.1$ & $122.2 \pm 28.8$ & 0.83 & $133.5 \pm 19.4$ & $126.3 \pm 32.2$ & 0.99 \\
\hline F12 \pm S.D. (\%) & $94.2 \pm 24.0$ & $92.4 \pm 18.8$ & 0.87 & $111.7 \pm 27.4$ & $105.8 \pm 30.0$ & 0.71 \\
\hline Plasminogen \pm s.D. (\%) & $92.9 \pm 11.0$ & $95.5 \pm 15.7$ & 0.55 & $95.5 \pm 26.4$ & $96.8 \pm 14.1$ & 0.16 \\
\hline S-Protein \pm S.D. (\%) & $84.7 \pm 21.4$ & $86.7 \pm 17.6$ & 0.67 & $87.2 \pm 23.8$ & $81.8 \pm 20.6$ & 0.23 \\
\hline PAl-1 \pm s.D. $(\mathrm{ng} / \mathrm{ml})$ & $47.5 \pm 20.8$ & $34.1 \pm 20.5$ & 0.004 & $41.6 \pm 22.5$ & $43.7 \pm 20.0$ & 0.45 \\
\hline TAT \pm s.D. $(\mu \mathrm{g} / \mathrm{l})$ & $6.3 \pm 5.5$ & $1.5 \pm 1.2$ & 0.0001 & $8.9 \pm 6.6$ & $9.5 \pm 7.1$ & 0.66 \\
\hline ATIII \pm S.D. (\%) & $114.8 \pm 9.4$ & $99.7 \pm 10.9$ & 0.0002 & $121.2 \pm 14.2$ & $119.3 \pm 14.4$ & 0.81 \\
\hline$\alpha_{2}$ antiplasmin \pm s.D. (\%) & $110.5 \pm 9.1$ & $96.2 \pm 13.8$ & 0.006 & $101.5 \pm 27.8$ & $113.8 \pm 13.4$ & 0.91 \\
\hline
\end{tabular}

Untreated, patients with untreated Cushing's syndrome; remission, patients with Cushing's syndrome in remission after surgery; persistent, patients with Cushing's syndrome with persistent hypercortisolism after surgery.

${ }^{a}$ VWF in all patients and after blood group correction. 

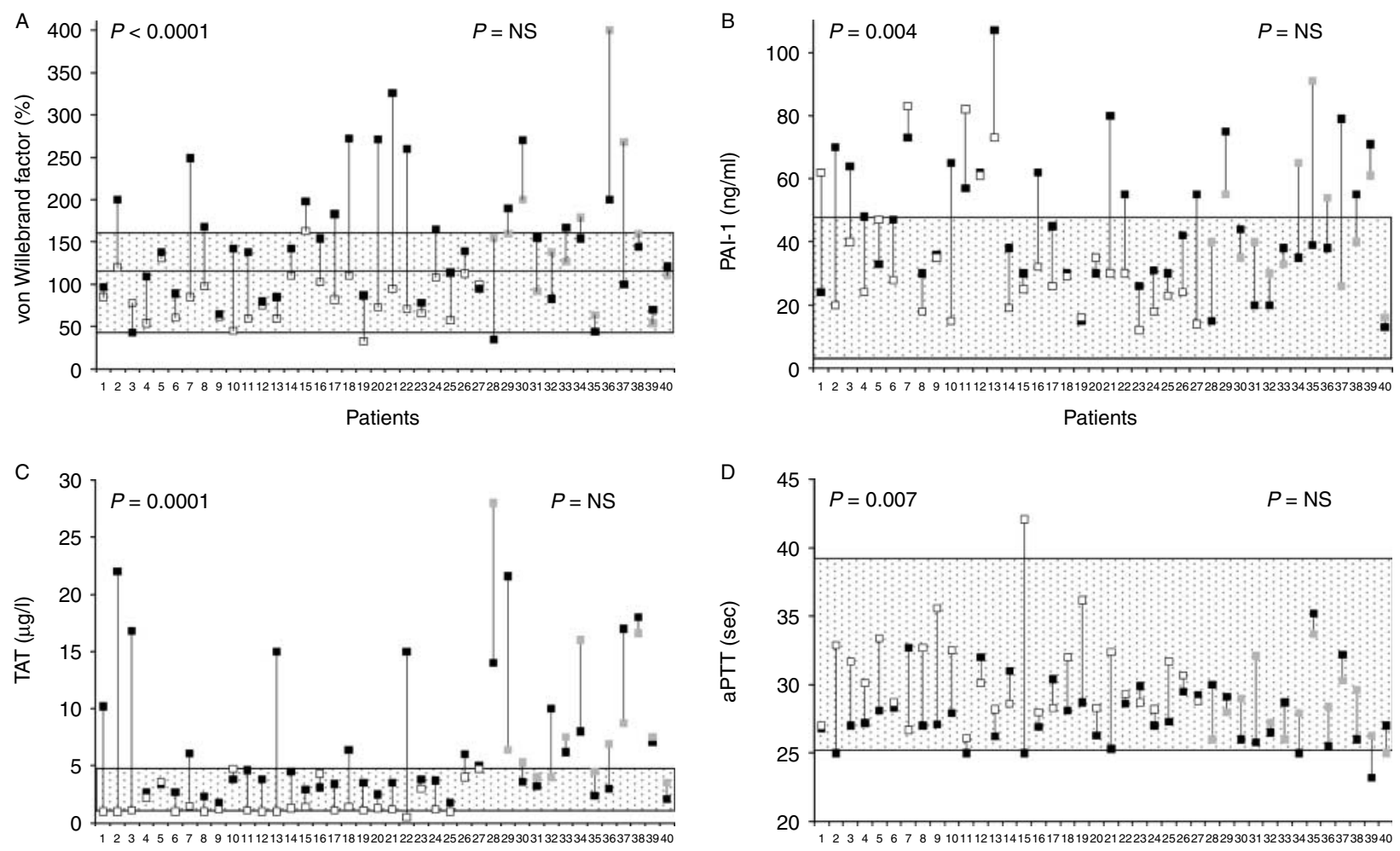

Patients

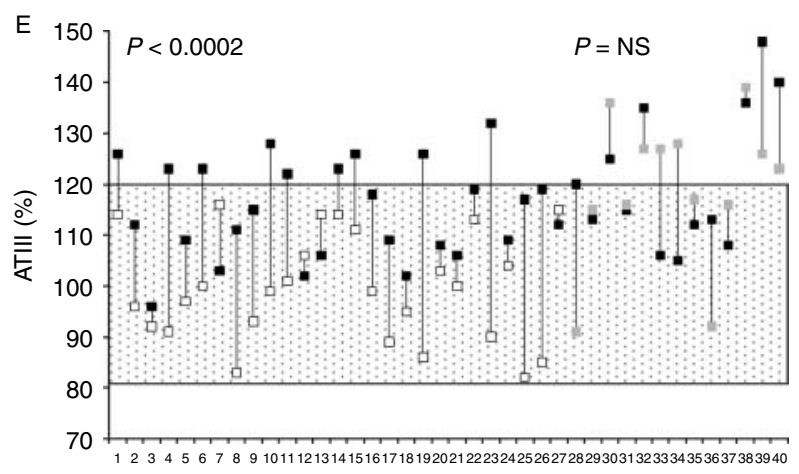

Patients

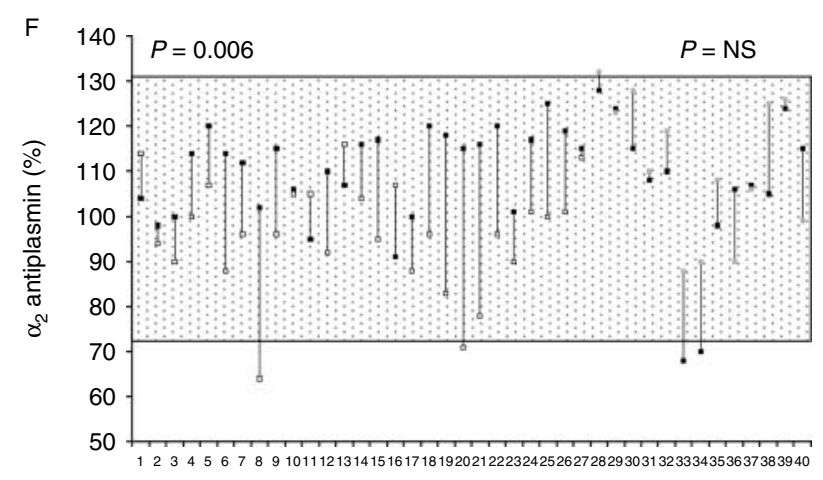

Patients

Figure 1 Changes in von Willebrand factor (A), plasminogen activator inhibitor antigen (PAI-1) (B), thrombin-antithrombin complex (TAT) (C), activated partial thromboplastin time (aPTT) (D), antithrombin III (ATIII) (E) and $\alpha_{2}$ antiplasmin (F) in untreated patients with Cushing's syndrome before and after surgery. The black, white and grey squares indicate untreated, remission and persistence patients respectively. The grey area indicates the normal limits of each parameter. In (A), were represented two normal ranges for 0 and non- 0 blood group.

controls. In addition, concentrations of VWF $(P<0.0001)$, TAT $(P=0.0001)$, ATIII $(P=0.0002)$, PAI-1 $(P=0.004), \alpha_{2}$ antiplasmin $(P=0.006)$ and aPTT $(P=0.007)$ tend to normalise after successful surgery. On the contrary, patients with persistent hypercortisolism after surgery did not have changes in mean values of coagulation parameters (Tables 3 and 4).

Despite the clinical data available, the pathogenesis of prothrombotic tendency is not yet clear. The most likely pathogenetic mechanism is represented by a cortisol-induced up-regulation of mRNA transcription of coagulation parameters and secondarily by the increased activity of fibrinolysis indexes $(24,25)$. VWF plays a major role in primary haemostasis by promoting blood platelet adhesion to the subendothelium of the vessel wall. Corticosteroids are known to increase plasma VWF concentrations by acting on the rate of synthesis by the endothelial cells of the vessel wall (26-28). In patients with CS, the increased plasma VWF levels are usually accompanied by an increase of TAT, as demonstrated in this study, which is an index of thrombin activity. 
Table 4 Number of patients with CS before and after surgery with coagulation indexes above normal ranges.

\begin{tabular}{|c|c|c|c|c|c|c|}
\hline & $\begin{array}{l}\text { Untreated } \\
(n=27)\end{array}$ & $\begin{array}{l}\text { Remission } \\
\quad(n=27)\end{array}$ & $\boldsymbol{P}$ & $\begin{array}{l}\text { Untreated } \\
(n=13)\end{array}$ & $\begin{array}{l}\text { Persistent } \\
\quad(n=13)\end{array}$ & $\boldsymbol{P}$ \\
\hline $\mathrm{aPTT}^{\mathrm{a}} \pm$ s.D. $^{\mathrm{a}}(\mathrm{s})$ & 0 & 0 & NS & 1 & 0 & NS \\
\hline Fibrinogen \pm s.D. $(\mathrm{mg} / \mathrm{dl})$ & 3 & 4 & NS & 3 & 3 & NS \\
\hline D-Dimer \pm s.D. $(\mathrm{mg} / \mathrm{l})$ & 7 & 5 & NS & 4 & 4 & NS \\
\hline $\mathrm{F} 1+2+$ S.D. $(\mathrm{nmol} / \mathrm{l})$ & 1 & 1 & NS & 1 & 0 & NS \\
\hline F5 \pm S.D. $(\%)$ & 2 & 0 & NS & 4 & 2 & NS \\
\hline F7士s.D. (\%) & 2 & 2 & NS & 3 & 2 & NS \\
\hline F8 \pm s.D. (\%) & 6 & 2 & NS & 2 & 2 & NS \\
\hline${ }^{\mathrm{b}} \mathrm{VWF} \pm$ s.D. (\%) All & 13 & 1 & 0.0003 & 7 & 6 & NS \\
\hline Blood group 0 ( $n=13 / 8)$ & 5 & 1 & NS & 4 & 4 & NS \\
\hline Blood group non-0 $(n=14 / 5)$ & 8 & 0 & 0.004 & 3 & 2 & NS \\
\hline F9 \pm s.D. (\%) & 6 & 3 & NS & 1 & 1 & NS \\
\hline F12 \pm S.D. (\%) & 1 & 0 & NS & 1 & 1 & NS \\
\hline Plasminogen \pm s.D. (\%) & 0 & 0 & NS & 0 & 0 & NS \\
\hline S-Protein \pm S.D. $(\%)$ & 0 & 0 & NS & 0 & 0 & NS \\
\hline C-Protein \pm S.D. (\%) & 7 & 2 & NS & 6 & 5 & NS \\
\hline PAl-1 \pm s.D. $(\mathrm{ng} / \mathrm{ml})$ & 12 & 5 & NS & 4 & 5 & NS \\
\hline TAT \pm S.D. $(\mu \mathrm{g} / \mathrm{l})$ & 9 & 5 & NS & 8 & 10 & NS \\
\hline ATIII \pm S.D. (\%) & 9 & 0 & 0.001 & 5 & 7 & NS \\
\hline$\alpha_{2}$ antiplasmin \pm s.D. (\%) & 0 & 0 & NS & 0 & 0 & NS \\
\hline
\end{tabular}

Untreated, patients with untreated Cushing's syndrome; remission, patients with Cushing's syndrome in remission after surgery; persistent, patients with Cushing's syndrome with persistent hypercortisolism after surgery.

apatients with concentrations under normal range.

bWF in all patients and after blood group correction.

PAI-1 is the main inhibitor of the fibrinolytic system; however, it is not clear if its abnormalities could be related to an increased risk factor for arterial thrombotic complications. In vitro studies have shown that corticosteroids can reduce fibrinolytic activity by inducing the release of PAI-1 in liver and fibrosarcoma cells (24). Previous studies reported controversial results about ATIII: sometimes it has increased or is unchanged in CS patients (10). ATIII inhibits activated
F8, F9, F10 and F12 and plays an important role in controlling coagulation, and its deficiency could be associated with thrombosis (29).

Our findings confirm, in a large population, the high levels of VWF with subsequent reduction of aPTT levels and evidence of enhanced thrombin generation (high concentrations of TAT) together with an impaired fibrinolytic activity (increased PAI-1, ATIII and $\alpha_{2}$ antiplasmin activities) in patients with untreated CS

Table 5 Coagulative and fibrinolytic parameters in patients with venous thromboembolic events.

\begin{tabular}{|c|c|c|c|c|}
\hline & $\begin{array}{l}\text { Coagulation } \\
\text { control } \\
(n=40)\end{array}$ & Patient 1 & Patient 2 & Patient 3 \\
\hline aPTT \pm s.D. (s) & $34.0 \pm 2.2$ & 27.2 & 28.2 & 28.4 \\
\hline Fibrinogen \pm s.D. $(\mathrm{mg} / \mathrm{dl})$ & $286.2 \pm 46.9$ & 393 & 345 & 320 \\
\hline D-Dimer \pm S.D. $(\mathrm{mg} / \mathrm{l})$ & $0.22 \pm 0.06$ & $0.52^{\mathrm{a}}$ & 0.22 & 0.24 \\
\hline $\mathrm{F} 1+2 \pm$ S.D. $(\mathrm{nmol} / \mathrm{l})$ & $0.54 \pm 0.16$ & 0.73 & 0.50 & 0.52 \\
\hline F5 \pm S.D. $(\%)$ & $102.2 \pm 12.7$ & 104 & 101 & 100 \\
\hline F7士s.D. (\%) & $97.6 \pm 24.1$ & 99 & 100 & 89 \\
\hline F8 \pm s.D. $(\%)$ & $109.0 \pm 11.8$ & 90 & 103 & 148 \\
\hline${ }^{b} \mathrm{VW} F \pm$ S.D. (\%) All & $84.4 \pm 20.9$ & - & - & - \\
\hline Blood group $0(n=21 / 21)$ & $83.8 \pm 21.1$ & 109 & $128^{\mathrm{a}}$ & - \\
\hline Blood group non-0 $(n=19 / 19)$ & $86.7 \pm 24.2$ & - & - & $240^{a}$ \\
\hline F9 \pm s.D. $(\%)$ & $119.3 \pm 13.7$ & $188^{\mathrm{a}}$ & 137 & 118 \\
\hline F12 \pm S.D. (\%) & $96.1 \pm 22.3$ & 81 & 96 & 98 \\
\hline Plasminogen \pm s.D. (\%) & $97.7 \pm 9.9$ & 86 & 82 & 94 \\
\hline S-Protein \pm s.D. $(\%)$ & $91.1 \pm 15.3$ & 86 & 90 & 85 \\
\hline C-Protein \pm s.D. (\%) & $120.0 \pm 19.3$ & 107 & 118 & 115 \\
\hline PAl-1 \pm s.D. $(\mathrm{ng} / \mathrm{ml})$ & $15.6 \pm 11.2$ & $48^{\mathrm{a}}$ & $63^{a}$ & $54^{a}$ \\
\hline TAT \pm S.D. $(\mu \mathrm{g} / \mathrm{l})$ & $3.0 \pm 1.4$ & 2.7 & 2.9 & $6.9^{\mathrm{a}}$ \\
\hline ATIII \pm S.D. $(\%)$ & $101.6 \pm 9.4$ & $123^{\mathrm{a}}$ & 114 & $135^{\mathrm{a}}$ \\
\hline$\alpha_{2}$ antiplasmin \pm s.D. (\%) & $99.9 \pm 8.9$ & 114 & 126 & 98 \\
\hline
\end{tabular}

Coagulation control: normal subjects for comparing coagulation indexes.

aPatients with altered coagulative parameters with respect to normal values (see 'Coagulation and fibrinolysis evaluation' section). bWF in all patients and after blood group correction. 
compared with normal subjects and patients with remission of hypercortisolism (Tables 2 and 3). In addition, VWF and ATIII mean levels were not only increased in active CS patients compared with cured patients and controls, but also above the normal ranges in a significant number of untreated patients (Table 4 and Fig. 1).

It has recently been observed that thromboembolic complications occur four times more frequently in patients with active $\mathrm{CS}$ and contribute to an increased mortality rate due to thromboembolic events (9). In a recent review, VTE not provoked by surgery were reported only in two studies with an incidence of one case $(1.9 \%)$ and six cases $(2.5 \%)$. The reported risk of postsurgery VTE was $<6 \%$ in seven studies and $20 \%$ in one study (23). In our population, the incidence of VTE was $7.5 \%$ : one case of PE immediately after surgery and two cases of DVT, one in an untreated patient and the other in a patient 2 months after surgery. Recent guidelines on CS did not address the prevention of thrombosis possibly due to the gaps in the various available studies (30). The only authors who focussed their attention on anticoagulant prophylaxis were Boscaro et al. (9) who analysed two groups with CS patients, one treated with heparin and/or warfarin. Survival analysis demonstrated a significantly higher morbidity and mortality due to VTE in the group not receiving anticoagulant prevention, suggesting that an adequate anticoagulant prophylaxis can reverse the prothrombotic state and avoid postoperative thromboembolic events in CS patients (9).

In conclusion, this study has showed the procoagulative phenotype due to cortisol-associated changes in haemostatic and fibrinolytic markers and the trend towards normalisation of some parameters after successful treatment. In turn, glucocorticoid excess in patients with CS and related changes in coagulation indexes lead to an increased risk of VTE. The risk factors for VTE in patients with CD could be i) degree and duration of hypercortisolism; ii) persistency of disease after treatment; iii) postoperative period; iv) coexistence of diabetes, obesity and hypertension and v) alterations of coagulation indexes. Therefore, we recommend performing the evaluation of haemostatic and fibrinolytic markers, or at least VWF, ATIII, aPPT and PAI in all patients with CS to identify those at high risk of VTE. It is not currently clear whether thromboprophylaxis should be undertaken in patients with CS, either only postoperative or throughout the disease activity. Therefore, it would be useful to perform a randomised, controlled study on the use of prophylaxis in patients with CS. Currently, thromboprophylaxis seems to be appropriated in patients with active disease particularly in the postoperative period. Moreover, thromboprophylaxis therapy must be done carefully by monitoring the patients to avoid a hypocoagulable state, which can be equally dangerous.

\section{Declaration of interest}

The authors declare that there is no conflict of interest that could be perceived as prejudicing the impartiality of the research reported.

\section{Funding}

This work was partially supported by grants from the University of Pisa (Fondi d'Ateneo) to E Martino.

\section{Acknowledgements}

We thank Prof. Aldo Pinchera (University of Pisa) for his continuous encouragement and advice.

\section{References}

1 Mancini T, Kola B, Mantero F, Boscaro M \& Arnaldi G. High cardiovascular risk in patients with Cushing's syndrome according to $1999 \mathrm{WHO} / \mathrm{ISH}$ guidelines. Clinical Endocrinology $2004 \mathbf{6 1}$ 768-777. (doi:10.1111/j.1365-2265.2004.02168.x)

2 Arnaldi G, Angeli A, Atkinson AB, Bertagna X, Cavagnini F, Chrousos GP, Fava GA, Findling JW, Gaillard RC, Grossman AB, Kola B, Lacroix A, Mancini T, Mantero F, Newell-Price J, Nieman LK, Sonino N, Vance ML, Giustina A \& Boscaro M. Diagnosis and complications of Cushing's syndrome: a consensus statement. Journal of Clinical Endocrinology and Metabolism 2003 88 5593-5602. (doi:10.1210/jc.2003-030871)

3 Arnaldi G, Mancini T, Polenta B \& Boscaro M. Cardiovascular risk in Cushing's syndrome. Pituitary 20047 253-256. (doi:10.1007/ s11102-005-1172-7)

4 Dekkers OM, Biermasz NR, Pereira AM, Roelfsema F, van Akeen MO, Voormolen JH \& Romijn JA. Mortality in patients treated for Cushing's disease is increased, compared with patients treated for non-functioning pituitary macroadenoma. Journal of Clinical Endocrinology and Metabolism 2007 92 976-981. (doi:10.1210/jc.2006-2112)

5 Small M, Lowe GD, Forbes CD \& Thomson JA. Thromboembolic complications in Cushing's syndrome. Clinical Endocrinology 1983 19 503-511. (doi:10.1111/j.1365-2265.1983.tb00025.x)

6 La Brocca A, Terzolo M, Pia A, Paccotti P, De Giuli P \& Angeli A. Recurrent thromboembolism as a hallmark of Cushing's syndrome. Journal of Endocrinological Investigation 199720 211-214.

7 Semple PL \& Laws ER Jr. Complications in a contemporary series of patients who underwent transsphenoidal surgery for Cushing's disease. Journal of Neurosurgery 199991 175-179. (doi:10.3171/ jns.1999.91.2.0175)

8 Sudhakar N, Ray A \& Vafidis JA. Complications after transsphenoidal surgery: our experience and a review of the literature. British Journal of Neurosurgery 200418 507-512. (doi:10.1080/ 02688690400012459)

9 Boscaro M, Sonino N, Scarda A, Barzon L, Fallo F, Sartori MT, Patrassi GM \& Girolami A. Anticoagulant prophylaxis markedly reduces thromboembolic complications in Cushing's syndrome. Journal of Clinical Endocrinology and Metabolism $2002 \mathbf{8 7}$ 3662-3666. (doi:10.1210/jc.87.8.3662)

10 Dal Bo Zanon R, Fornasiero L, Boscaro M, Cappellato G, Fabris F \& Girolami A. Increased factor VIII associated activities in Cushing's syndrome: a probable hypercoagulable state. Thrombosis and Haemostasis 198247 116-117.

11 Patrassi GM, Sartori MT, Viero ML, Scarano L, Boscaro M \& Girolami A. The fibrinolytic potential in patients with Cushing's disease: a clue to their hypercoagulable state. Blood Coagulation \& Fibrinolysis 19923 789-793. (doi:10.1097/00001721-1992 12000-00013)

12 Fatti LM, Bottasso B, Invitti C, Coppola R, Cavagnini F \& Mannucci PM. Marker of activation of coagulation and fibrinolysis in patients with Cushing's syndrome. Journal of Endocrinological Investigation 200023 145-150. 
13 Ikkala E, Myllylä G, Pelkonen R, Rasi V, Viinikka L \& Ylikorkala O. Haemostatic parameters in Cushing's syndrome. Acta Medica Scandinavica $1985 \mathbf{2 1 7}$ 507-511. (doi:10.1111/j.0954-6820. 1985.tb03254.x)

14 Patrassi GM, Dal Bo Zanon R, Boscaro M, Martinelli S \& Girolami A. Further studies on the hypercoagulable state of patients with Cushing's syndrome. Thrombosis and Haemostasis 198530 518-520.

15 Patrassi GM, Sartori MT, Livi U, Casonato A, Danesin C, Vettore S \& Girolami A. Impairment of fibrinolytic potential in long-term steroid treatment after heart transplantation. Transplantation 199764 1610-1614. (doi:10.1097/00007890-199712150$00021)$

16 Ambrosi B, Sartorio A, Pizzocaro A, Passini E, Bottasso B \& Federici A. Evaluation of haemostatic and fibrinolytic markers in patients with Cushing's syndrome and in patients with adrenal incidentaloma. Experimental and Clinical Endocrinology and Diabetes 2000108 294-298. (doi:10.1055/s-2000-8000)

17 Squizzato A, Gerdes VEA, Ageno W \& Buller HR. The coagulation system in endocrine disorders: a narrative review. Internal and Emergency Medicine 20072 76-83. (doi:10.1007/s11739-0070026-X)

18 Kastelan D, Dusek T, Kraljevic I, Polasek O, Giljevic Z, Solak M, Zupanic Salek S, Jelcic J, Aganovic I \& Korsic M. Hypercoagulability in Cushing's syndrome: the role of specific haemostatic and fibrinolytic markers. Endocrine 200936 70-74. (doi:10.1007/ s12020-009-9186-y)

19 Erem C, Nuhoglu I, Yilmaz M, Kocak M, Demirel A, Ucuncu O \& Onder Ersoz H. Blood coagulation and fibrinolysis in patients with Cushing's syndrome: increased plasminogen activator inhibitor-1, decreased tissue factor pathway inhibitor, and unchanged thrombin-activatable fibrinolysis inhibitor levels. Journal of Endocrinological Investigation 200932 169-174.

20 Nieman LK, Biller BM, Findling JW, Newell-Price J, Savage MO, Stewart PM \& Montori VM. The diagnosis of Cushing's syndrome: an endocrine society clinical practice guideline. Journal of Clinical Endocrinology and Metabolism 200893 1526-1540. (doi:10. 1210/jc.2008-0125)

21 Boscaro M \& Arnaldi G. Approach to the patient with possible Cushing's syndrome. Journal of Clinical Endocrinology and Metabolism 200994 3121-3131. (doi:10.1210/jc.2009-0612)

22 Franchini M, Lippi G, Manzato F, Vescovi PP \& Targher G. Hemostatic abnormalities in endocrine and metabolic disorders. European Journal of Endocrinology 2010 162 439-451. (doi:10. 1530/EJE-09-0958)
23 Van Zaane B, Nur E, Squizzato A, Dekkers OM, Twickler MB, Fliers E, Gerdes VEA, Büller HR \& Brandjes PM. Hypercoagulable state in Cushing's syndrome: a systematic review. Journal of Clinical Endocrinology and Metabolism 200994 2743-2750. (doi:10. 1210/jc.2009-0290)

24 Healy AM \& Gelehrter TD. Induction of plasminogen activator inhibitor-1 in HepG2 human hepatoma cells by mediators of the acute phase response. Journal of Biological Chemistry 1994269 19095-19100.

25 Halleux CM, Declerck PJ, Tran SL, Detry R \& Brichard SM. Hormonal control of plasminogen activator inhibitor-1 gene expression and production in human adipose tissue: stimulation by glucocorticoids and inhibition by catecholamines. Journal of Clinical Endocrinology and Metabolism $1999 \mathbf{8 4} 4097-4105$. (doi:10.1210/jc.84.11.4097)

26 Casonato A, Pontara E, Boscaro M, Sonino N, Sartorello F, Ferrasin S \& Girolami A. Abnormalities of von Willebrand factor are also part of the thrombotic state of Cushing's syndrome. Blood Coagulation and Fibrinolysis 199910 145-151. (doi:10.1097/ 00001721-199904000-00006)

27 Casonato A, Daidone V, Sartorello F, Albiger N, Romualdi C, Mantero F, Pagnan A \& Scaroni C. Polymorfisms in von Willebrand factor gene promoter influence the glucocorticoid-induced increase in von Willebrand factor: the lesson learned from Cushing syndrome. British Journal of Haematology $2008 \mathbf{1 4 0}$ 230-235. (doi:10.1111/j.1365-2141.2007.06907.x)

28 Denis CV. von Willebrand factor in vascular pathophysiology. Pathologie et Biologie 200351 395-396. (doi:10.1016/S03698114(03)00025-7)

29 Bayston TA \& Lane DA. Antithrombin: molecular basis of deficiency. Thrombosis and Haemostasis 199778 339-343.

30 Biller BM, Grossman AB, Stewart PM, Melmed S, Bertagna X, Bertherat J, Buchfelder M, Colao A, Hermus AR, Hofland LJ, Klibanski A, Lacroix A, Lindsay JR, Newell-Price J, Nieman LK, Petersenn S, Sonino N, Stalla GK, Swearingen B, Vance ML, Wass JA \& Boscaro M. Treatment of adrenocorticotropindependent Cushing's syndrome: a consensus statement. Journal of Clinical Endocrinology and Metabolism 200893 2454-2462. (doi:10.1210/jc.2007-2734)

Received 5 August 2010

Accepted 9 August 2010 